\title{
Athetoid Cerebral Palsy
}

National Cancer Institute

\section{Source}

National Cancer Institute. Athetoid Cerebral Palsy. NCI Thesaurus. Code C97169.

A subtype of cerebral palsy characterized by involuntary, purposeless writhing movements which affect the hands, feet, arms, and legs; the face and tongue may be affected as well, leading to involuntary grimacing, drooling, dysarthria and difficulty eating. 